Article

\title{
Unravelling the Role of Nitrogen in Surface Chemistry and Oxidation Evolution of Deep Cryogenic Treated High-Alloyed Ferrous Alloy
}

\author{
Patricia Jovičević-Klug ${ }^{1,2, * \mathbb{D}}$, Matic Jovičević-Klug ${ }^{3}{ }^{\mathbb{D}}$ and Bojan Podgornik ${ }^{1,2}$ \\ 1 Department of Metallic Materials and Technology, Institute of Metals and Technology, Lepi pot 11, \\ 1000 Ljubljana, Slovenia; bojan.podgornik@imt.si \\ 2 Jožef Stefan International Postgraduate School, Jamova cesta 39, 1000 Ljubljana, Slovenia \\ 3 Department of Microstructure Physics and Alloy Design, Max Planck Institute for Iron Research, \\ Max-Planck-Straße 1, 40237 Düsseldorf, Germany; m.jovicevic-klug@mpie.de \\ * Correspondence: patricia.jovicevicklug@imt.si; Tel.: +386-14701-990
}

check for

updates

Citation: Jovičević-Klug, P.; Jovičević-Klug, M.; Podgornik, B. Unravelling the Role of Nitrogen in Surface Chemistry and Oxidation Evolution of Deep Cryogenic Treated High-Alloyed Ferrous Alloy. Coatings 2022, 12, 213. https://doi.org/ 10.3390 /coatings12020213

Academic Editor: Francesco Di Quarto

Received: 12 January 2022

Accepted: 4 February 2022

Published: 6 February 2022

Publisher's Note: MDPI stays neutral with regard to jurisdictional claims in published maps and institutional affiliations.

Copyright: (C) 2022 by the authors. Licensee MDPI, Basel, Switzerland. This article is an open access article distributed under the terms and conditions of the Creative Commons Attribution (CC BY) license (https:// creativecommons.org/licenses/by/ $4.0 /)$.

\begin{abstract}
The role of nitrogen, introduced by deep cryogenic treatment (DCT), has been investigated and unraveled in relation to induced surface chemistry changes and improved corrosion resistance of high-alloyed ferrous alloy AISI M35. The assumptions and observations of the role of nitrogen were investigated and confirmed by using a multitude of complementary investigation techniques with a strong emphasis on ToF-SIMS. DCT samples display modified thickness, composition and layering structure of the corrosion products and passive film compared to a conventionally heat-treated sample under the same environmental conditions. The changes in the passive film composition of a DCT sample is correlated to the presence of the so-called ghost layer, which has higher concentration of nitrogen. This layer acts as a precursor for the formation of green rust on which magnetite is formed. This specific layer combination acts as an effective protective barrier against material degradation. The dynamics of oxide layer build-up is also changed by DCT, which is elucidated by the detection of different metallic ions and their modified distribution over surface thickness compared to its CHT counterpart. Newly observed passive film induced by DCT successfully overcomes the testing conditions in more extreme environments such as high temperature and vibrations, which additionally confirms the improved corrosion resistance of DCT treated high-alloyed ferrous alloys.
\end{abstract}

Keywords: deep cryogenic treatment; nitrogen; passive film; ToF-SIMS; surface chemistry; corrosion resistance

\section{Introduction}

One of the challenges in numerous industries is corrosion of the material (degradation of material), especially in industries involved with the application of metallic materials or their production (such as steel and tool industry [1], oil and gas industry [2], medicine [3], electronic industry [4], automotive industry [5], aerospace industry [6] and nuclear industry [7]). Corrosion resistance of metallic surfaces can be enhanced by various methods. Heat treatment, as one such method, is used to tailor the microstructure of metallic material and with it the surface characteristics and behavior, which in turn influences the corrosion resistance of the treated metals [8]. One of the potentially developing heat treatment methods is deep cryogenic treatment (DCT), in which on one hand the impact on the climate is minimal and the costs of production are low [9], and on the other hand, the modification of metallic material is induced from the surface down to the bulk core [10]. During DCT the material is exposed to cryogenic temperatures (under $-160{ }^{\circ} \mathrm{C}$ and usually in liquid nitrogen $\left(\mathrm{N}_{2}\right)$ ) in order to improve mechanical properties such as hardness [11] and fracture toughness [12]. However, DCT can also improve the oxidation behavior of a metallic surface and improve corrosion resistance $[1,13]$. The effect of DCT on corrosion resistance 
of ferrous alloys has been associated with the altercation of their microstructure $[1,13,14]$, oxidation behavior of the surface layer [15] and modification of the development dynamics of corrosion products [13]. However, the corrosion resistance of ferrous alloys and its modification through heat treatment is also influenced by three main factors: the chemical composition of ferrous alloys [16], the corrosion environment [17] and biophysical factors [17]. The corrosion resistance and its modification with previously mentioned factors is often discussed in connection to the development of a passivation layer and its degradation and reformation with temporal corrosion progress. The corrosion dynamics of passive film composition and breakdown of passive film of ferrous alloys have been widely studied solely in connection to stainless steels. Furthermore, the research on the role of alloying elements in steel materials has been mainly focused on $\mathrm{Cr}$ and its common corrosion products, such as $\mathrm{Cr}$ (III) oxide and hydroxide, which are believed to play the main role in passive film [18]. The research on the effect of other alloying elements on corrosion resistance is seldom researched and is thus highly dubious.

The beneficial effect of $\mathrm{N}$ on passive film and corrosion resistance, has been studied in connection with stainless steels, for which $\mathrm{N}$ has been shown to play an important role in decreasing weight loss of material and increasing the pitting potential [18]. Additionally, $\mathrm{N}$ is believed to accelerate repassivation of stainless steels, especially in the presence of dissolved chloride $[13,18]$. $\mathrm{N}$ presence in passive film in stainless steels was determined to be in elemental form incorporated within the metallic matrix (solid solution) or chemically bound in various compounds (nitrides, nitrates, nitrites). $\mathrm{N}$ can participate and influence corrosion processes during exposure of material to corrosive environments when $\mathrm{N}$ is part of the metallic surface (in the matrix as alloying element [19] or later added during the process of nitriding [20]) or as part of a passive film in the form of dissolved species (such as NHX). The interfacial $\mathrm{N}$ was proven to be negatively charged, which can influence the passivation film dynamics [18]. There are some studies performed in correlation to $\mathrm{N}$ presence in metallic matrix, which indicate that $\mathrm{N}$ improves corrosion resistance. However, there is a lack of studies correlating the presence of $\mathrm{N}$ with dynamics of the passive film [18]. There are three possible mechanisms responsible for the influence of $\mathrm{N}$ on the corrosion properties, which are merely based on observation of stainless steels:

(1) Anodic segregation of $\mathrm{N}$ during dissolution, which can act as a barrier in active dissolution and consequently changes the passivation process, which then influences the corrosion resistance [21].

(2) The increase of $\mathrm{pH}$ in pits is a consequence of the formation of ammonium ions, which buffer the solution of passive film regions [22].

(3) Negatively charged $\mathrm{N}$ ions and uncharged $\mathrm{N}$ enrichment beneath the passive film reduce the electric potential difference, which effectively acts as a protective layer of the passivation layer [21,22]. The interphase region directly between the metallic surface and passive film (active dissolution and active passivation) has not been researched in detail.

The literature review showed that there is a lack of studies on the DCT effect in correlation to the role of $\mathrm{N}$ on corrosion behavior and surface modification as well as passive film build-up in high-alloyed ferrous alloys. Previous studies mostly concentrated on improving the corrosion resistance of predominantly low-alloyed ferrous alloys [23-25], with a handful of research studies performed on high-alloyed steels such as stainless steels and maraging steels [26-29]. However, in addition to these two classes there is an extensive group of other high-alloyed ferrous alloys, such as high-strength steels, heat-resistant ferrous alloys, low-density ferrous alloys, etc., which are used in corrosive environments and require sufficient corrosion resistance for their application. This indicates that there is a considerable research gap in this field with great potential to understand and explain the effect of DCT on the corrosion behavior of high-alloyed ferrous alloys. Furthermore, this study is a follow-up study of previous surface and corrosion investigations of highalloyed ferrous alloys from our group. Jovičević-Klug et al. $2021[13,15]$ focused on the effect of DCT in relation to alloying elements $(\mathrm{Co}, \mathrm{Cr}, \mathrm{Fe}, \mathrm{V}, \mathrm{W})$, surface modification 
and the $\mathrm{N}$ dynamic in DCT-treated tool steels. It was determined that these different factors result in improved corrosion properties with DCT, which was also observed by our previous study, Voglar et al. 2021 [1]. The changes to high-alloyed ferrous alloy AISI M35 were observed after DCT in correlation with surface chemistry and surface modification, which indicated that DCT samples display a different evolution of corrosion products compared to conventionally heat-treated ones. It was discovered that green rust (GR) plays an important role in increased corrosion resistance of DCT samples through preferential build-up of magnetite over the pre-existing GR layer. The main open question is the exact understanding of how GR is incorporated into the corrosion development and how the nitrogen is influencing such development. For these reasons, this study continues to further elucidate the corrosion and oxidative behavior of the surface of AISI M35 in more detail with correlative investigation with optical microscopy $(\mathrm{OM})$, scanning electron microscopy (SEM), energy-dispersive $\mathrm{X}$-ray spectroscopy (EDS), time-of-flight secondary ion mass spectroscopy (ToF-SIMS) and X-ray diffraction (XRD) methods. Furthermore, this paper also aims to demonstrate the advantages of DCT in regards to corrosion behavior of high-alloyed ferrous alloys by revealing surface-sensitive details related to $\mathrm{N}$ dynamics and GR.

\section{Materials and Methods}

\subsection{Materials and Experimental Details}

The selected high-alloyed ferrous alloy was high-speed steel AISI M35, provided by SIJ Metal, Ravne (Slovenia). This alloy was selected based on our previous research and due to its lower corrosion resistance, making it easier to follow, and explain in detail, dynamic surface chemistry and corrosion behavior in relation to DCT-induced changes, when the alloy is exposed to chloride-ions-enriched medium. The chemical composition of the investigated material is in wt.\%, $0.90 \mathrm{C}, 0.34 \mathrm{Mn}, 0.004 \mathrm{~S}, 4.10 \mathrm{Cr}, 5.20 \mathrm{Mo}, 6.22 \mathrm{~W}, 2.01 \mathrm{~V}$, $4.52 \mathrm{Co}$ and $76.70 \mathrm{Fe}$. For the experiments cube samples $(10 \mathrm{~mm} \times 10 \mathrm{~mm} \times 10 \mathrm{~mm})$ were used. Samples were prepared with two different heat treatments: the first was conventional heat treatment (CHT), performed according to the steel producer recommendations with quenching in nitrogen gas at $5 \mathrm{bar}$, and the second was DCT, performed by controlled gradual immersion of material into liquid nitrogen (austenitization temperature 1160/2 min and tempering temperature $620 / 2 \mathrm{~h}(3 \times$ cycles for $\mathrm{CHT}$ and $1 \times$ cycle for DCT after DCT)). The soaking time of DCT was $24 \mathrm{~h}$, the soaking temperature was $-196^{\circ} \mathrm{C}$ and the warming/cooling rate was approximately $10^{\circ} \mathrm{C} \cdot \mathrm{min}^{-1}$, with DCT placed after quenching and before a single step of tempering. The samples were mechanically grounded with silicon carbide $(\mathrm{SiC})$ emery paper down to 1000 grit and then polished with diamond paste down to $1 \mu \mathrm{m}$, and as the last step they were ultrasonically rinsed in alcohol. The polished samples $(\mathrm{Ra}=0.05 \mu \mathrm{m})$ were then immersed in chloride-ions-enriched medium seawater ( $\mathrm{pH} 8.22 \pm 0.08$, salinity $37.31 \% \pm 1.50 \%$; all other water-soluble ions are in $\mu \mathrm{mol} \cdot \mathrm{L}^{-1}: \mathrm{NO}_{2}{ }^{-} 0.09 \pm 0.12, \mathrm{NO}_{3}{ }^{-} 0.38 \pm 0.27, \mathrm{PO}_{4}{ }^{3-} 0.05 \pm 0.01, \mathrm{NH}_{4}{ }^{+} 0.45 \pm 0.36$, $\mathrm{SO}_{4}{ }^{2-} 1.48 \pm 1.70, \mathrm{Na}^{+} 1.96 \pm 1.19, \mathrm{Mg}^{2+} 0.42 \pm 0.27, \mathrm{Ca}^{2+} 1.49 \pm 0.96, \mathrm{Cl}^{-} 1.15 \pm 0.68, \mathrm{~K}^{+}$ $0.30 \pm 0.35$ ) for 1 day in and 7 days.

In order to enhance the role of nitrogen and alloying elements $(\mathrm{Co}, \mathrm{Cr}, \mathrm{Fe}, \mathrm{V}, \mathrm{W})$ as potential corrosion inhibitors in DCT-treated high-alloyed ferrous alloy, two additional $1 \mathrm{~h}$ tests with different corrosion environments were performed, one with elevated temperature, where the chloride-ions-enriched medium was heated up to $100{ }^{\circ} \mathrm{C}(\mathrm{CHT}+\mathrm{T} / \mathrm{DCT}+\mathrm{T})$ and another with elevated temperature and vibration, with chloride-ions enriched heated up to $100{ }^{\circ} \mathrm{C}$ and specimens subjected to vibrations of $25 \mathrm{~Hz}(\mathrm{CHT}+\mathrm{T}+\mathrm{V} / \mathrm{DCT}+\mathrm{T}+\mathrm{V})$. Elevated temperatures of corrosion environment lead to higher corrosion rates of ferrous alloys because of the increase in electrochemical reactions at higher temperatures, being also strongly affected by chemical compositions and microstructure of the alloy [30]. Vibrations on the other hand can have diverse effect on corrosion resistance of ferrous alloys, either improving or deteriorating it due to the acoustic cavitation and delamination of corrosion 
products [31]. Afterwards, for the study of pitting corrosion, the corrosion products were removed from the sample surfaces according to C.3.1. G1-90 ASTM standard [32].

\subsection{Microstructure and Oxide Characterization}

The surface of samples was firstly investigated with light optical microscope (LM), Zeiss Axio Vario, Carl Zeiss, Oberkochen, Germany and then with a scanning electron microscope (SEM), JEOL JSM-6500F, Jeol, Tokyo, Japan and locally chemically analyzed using energy-dispersive spectroscopy (EDX), Oxford EDS INCA Energy 450, Oxford Instruments, Abingdon, UK. The detailed microstructure and corrosion products analyses for high-alloyed ferrous alloy AISI M35 is based on our previous studies by Jovičević-Klug et al. 2020 [33] and Jovičević-Klug et al. 2021 [13]. The phase/oxide characterization and identification were performed by XRD, PANalytical 3040/60, Almelo, The Netherlands. The XRD data were measured from $15^{\circ}$ to $90^{\circ}$ of the $2 \theta$ angle. The phase identification was performed using COD database references on a selected location.

\subsection{Surface Characterization}

Electrochemical results are based on results of the study of Voglar et al. 2021 [1], whereas the main values are provided in Supplementary Material 1. After corrosion products removal, the topography analysis of samples and evaluation of pitting depth was performed by focus variation microscopy with Alicona InfiniteFocus, Bruker, Graz, Austria. The local chemistry of the surface and in-depth chemical profiles were performed by time-of-flight secondary ion mass spectroscopy (ToF-SIMS), IONTOF GmbH, Münster, Germany. The primary beam was $\mathrm{Bi}_{3}{ }^{+}$with energy of $30 \mathrm{keV}$. The analytical velocity of the depth profile was $0.2 \mathrm{~nm} / \mathrm{s}$ and the detection limit of the oxide/metal interface species was around $1 \mathrm{ppm}$. The areas of $250 \times 250 \mu \mathrm{m}^{2}(512 \times 512 \mathrm{px})$ and $50 \times 50 \mu \mathrm{m}^{2}(256 \times 256 \mathrm{px})$ were measured with positive and negative surface spectra (secondary ions in the range $\mathrm{m} / \mathrm{z}$ of 0-875), with $180 \mathrm{~nm}$ lateral resolution. The angle of ions was $45^{\circ}$ and etching in-profile was performed by $\mathrm{Cs}(2 \mathrm{keV})$. The correction of results was performed according to Poisson statistics [34]. The statistics were performed in SPSS (PASWStatistics18). The influence of topography is also considered in the interpretation of the individual 2D ToF-SIMS images through the total-ion signal images. The total-ion signal images for all the investigated sample surface are provided for reference in Supplementary Material 2.

\section{Results and Discussion}

\subsection{Corrosion Products}

To confirm the testing conditions also control groups with synthetic chloride-ionsenriched medium-synthetic saltwater $(3.5 \% \mathrm{NaCl})$ were performed, which provided similar results of evolution and presence of corrosion products, for both CHT and DCT sample groups. However, the major difference compared to natural seawater was that less intense signals of corrosion products were observed for the synthetic one. In order to enhance the corrosion and to emphasize the differences between the two treatment groups (CHT and DCT) natural seawater was selected. The first set of specimens (control group) was exposed to chloride-ions-enriched medium at room temperature (CHT/DCT), aimed at verifying the observations from our previous studies. The XRD data showed that generally the corrosion products after 1 and 7 days exposure (Figure 1a) are similar for both heat treatments (CHT and DCT). The main identified phases on the surface of all tested samples are mainly calcium carbonate $\left(\mathrm{CaCO}_{3}\right)$, halite $(\mathrm{NaCl})$, iron as matrix $(\mathrm{Fe})$, carbides, goethite $(\alpha-\mathrm{FeO}(\mathrm{OH})$; Figure $1 \mathrm{~b})$, lepidocrocite $(\gamma-\mathrm{FeO}(\mathrm{OH})$; Figure $1 \mathrm{c})$, magnetite $\left(\mathrm{Fe}_{3} \mathrm{O}_{4} ;\right.$ Figure $\left.1 \mathrm{~d}\right)$ and green rust (GR I and GR II; Figure 1e). In our previous study [13], the presence of other oxides was also confirmed, but they are not relevant to this study due to their lower volumetric presence within the surface. The observation of GR I+II also confirmed our previous findings that GR I+II is predominantly present on DCT samples, on which, later in time, magnetite $\left(\mathrm{Fe}_{3} \mathrm{O}_{4}\right)$ is formed. It is suggested that $\mathrm{GR}$ is formed due to the presence of newly formed anions $\left(\mathrm{NO}_{3}{ }^{-}, \mathrm{SO}_{4}{ }^{2-}\right.$ and $\left.\mathrm{Cl}^{+}\right)$that compensate the pre-existing ammonium 
cations $\left(\mathrm{NH}_{4}{ }^{+}\right)$. The main sources of nitrogen for GR for both heat treatment groups are suggested to be ions presence in chloride-ions-enriched medium and the metallic surface of AISI M35. In order to observe dynamics of nitrogen and other alloying elements (Co, $\mathrm{Cr}$, $\mathrm{Fe}, \mathrm{V}, \mathrm{W}$ ) in correlation with GR I+II and magnetite, which could act as the base underlying corrosion products (denoted as passive film), the samples with 1 day exposure in chlorideions-enriched medium were selected for further study. Samples exposed for 7 days develop extended presence of other corrosion products that obscure the underlying initial corrosion layers relevant for this research.

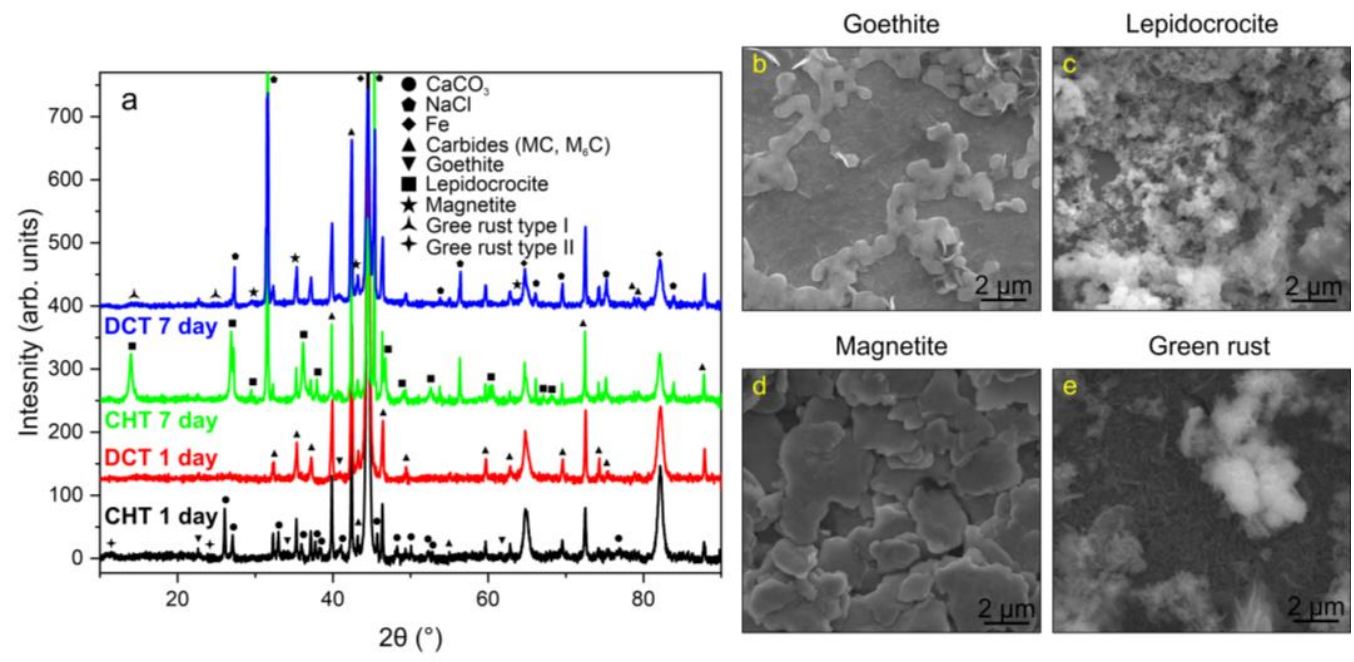

Figure 1. (a) The XRD data of corrosion products for 1 day and 7 days exposure in chloride-ionsenriched medium. (b-e) Observed corrosion products.

\subsection{Characterization of Layers}

The characterization of layers (oxide layer, passive film and modified layer (ghost layer)) for both heat-treated samples (CHT and DCT) after 1 day exposure was investigated by SEM/EDX and SEM-FIB techniques in combination with XRD data and supplementary ToF-SIMS technique. The SEM/EDX-FIB analysis provided insight into the dynamics of selected alloying elements $(\mathrm{Cr}, \mathrm{Fe}, \mathrm{V}, \mathrm{W}, \mathrm{Mo})$, whereas $\mathrm{Co}$ is excluded due to its homogenous distribution in both samples. The cross-section of $\mathrm{CHT}$ sample revealed that beside $\mathrm{O}$, also $\mathrm{Cr}, \mathrm{Fe}, \mathrm{Mo}, \mathrm{W}$ and $\mathrm{V}$ act as the main elements within the surface interphase between the metallic surface and corrosive environment, presented in Supplementary Material 3. In the DCT sample, similar results were obtained (Supplementary Material 3) with one major difference. In the DCT sample, a layer enriched with $\mathrm{N}$ and depleted of other elements, previously dubbed the "ghost layer" [35] is formed between the metallic surface and the oxide layer. The passive film, which is correlated with the improved corrosion resistance (Supplementary Material 1), is suggested to be enriched with N-dissolved species and acts as the inhibitor for the GR I+II growth in DCT samples and, later, magnetite (Figure 2a,d). This phenomenon (passive film induced by DCT) is observed in correlation to DCT and corrosion properties of high-alloyed ferrous alloys for the first time. In addition to this layer, the specific development of overlaying oxide layer (partly part of passive film) is also found, at which the first inner layer is determined to be magnetite and afterwards the outer layer is composed of other oxide/hydroxide species that are also present for CHT sample. In addition, in the DCT sample minor depletion of alloying elements is observed, which is explained to originate from the protection barrier formed by the passive film as presented in Figure 2c,d. 

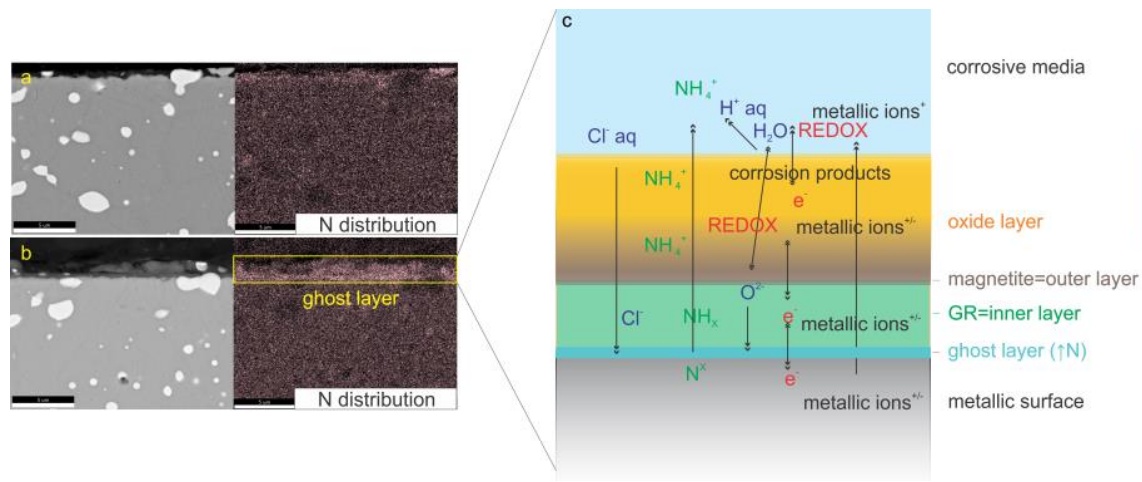

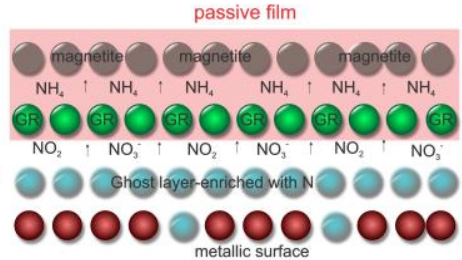
Figure 2. (a) SEM-mapping results of CHT sample, (b) SEM-mapping results of DCT sample,
(c) schematic representation of layers and (d) the schematic representation of passive film and ghost layer in DCT sample.

\subsection{ToF-SIMS Surface Analyses}

To provide a deeper insight into the newly observed surface chemistry dynamic of the passive film and ghost layer in correlation to GR in a DCT sample, ToF-SIMS surface analysis and in-depth profiling (Chapter 3.4) were carried out on CHT and DCT specimens after 1 day exposure in chloride-ions-enriched medium at room temperature $\left(21^{\circ} \mathrm{C}\right)$. The ToF-SIMS images were used to identify differences in the surface distribution of ionic species related to corrosion product and their development on the samples' surface. The samples are assumed to be chemically and microstructurally homogenous and the corrosion products (oxide layer) and passive layer are homogeneously distributed on the sample surface. Nitrogen content $(\mathrm{N})$ was measured with $\mathrm{CN}^{-}$signal, due to the small ionization yield of $\mathrm{N}$ with ToF-SIMS. To indirectly indicate the corrosion propagation of samples, the isotope behavior of $\mathrm{Cl}$ was tracked, as $\mathrm{Cl}$ is the element with highest electron affinity that can be present within the corrosion products. For this reason, the mapping of $\mathrm{Cl}^{-}$ion and its isotope variants ${ }^{35} \mathrm{Cl} /{ }^{37} \mathrm{Cl}$ were measured. Furthermore, to track the dynamics of other main alloying elements $(\mathrm{C}, \mathrm{Co}, \mathrm{Cr}, \mathrm{Fe}, \mathrm{V}$ and $\mathrm{W})$, both negative and positive polarity measurements were performed. The species selected for each selected alloying element are: $\mathrm{C}\left(\mathrm{C}^{-}, \mathrm{CH}^{-}, \mathrm{C}_{2}{ }^{-}, \mathrm{C}_{2} \mathrm{H}^{-}, \mathrm{CHO}_{2}{ }^{-}, \mathrm{C}_{2} \mathrm{H}_{2} \mathrm{O}_{2}{ }^{-}\right), \mathrm{Cr}\left(\mathrm{Cr}^{+}, \mathrm{CrOH}^{-}\right), \mathrm{Co}\left(\mathrm{Co}^{+}, \mathrm{CoO}^{-}\right), \mathrm{Cl}$ $\left(\mathrm{Cl}^{-}\right), \mathrm{Fe}\left(\mathrm{Fe}^{+},{ }^{54} \mathrm{Fe}^{+}, \mathrm{FeH}^{+}\right), \mathrm{N}\left(\mathrm{CN}^{-}\right), \mathrm{V}\left(\mathrm{V}^{+}, \mathrm{VO}^{-}\right), \mathrm{W}\left({ }^{186} \mathrm{WO}_{4} \mathrm{H}^{-}, \mathrm{WO}_{4} \mathrm{H}^{-},{ }^{183} \mathrm{WO}_{4} \mathrm{H}^{-}\right.$, $\left.{ }^{182} \mathrm{WO}_{4} \mathrm{H}^{-},{ }^{186} \mathrm{WO}_{3}{ }^{-},{ }^{183} \mathrm{WO}_{3}{ }^{-},{ }^{182} \mathrm{WO}_{3}{ }^{-}, \mathrm{WO}_{3}{ }^{-}\right)$. Unfortunately, no Mo species could be detected for the description of Mo dynamics.

Figures 3-5 show the results of low-magnification ToF-SIMS analysis of both polarities, presenting cumulative ion images of selected ion species for individual elements. The first image (Figures 3a, 4a and 5a,b) presents the distribution of $\mathrm{Cl}^{-}$ions, because it can indicate the passive film structure through its incorporation within the passive film and can possibly explain the breakdown dynamics [36] of the "ghost layer" formed by DCT. The comparison of CHT (Figure 3a) and DCT (Figure 4a) samples clearly shows higher abundance of $\mathrm{Cl}^{-}$ ions for $\mathrm{Cl}$ of nitrides in $\mathrm{CHT}$ sample in the martensitic matrix of the sample. This provides one of the first pieces of direct evidence that DCT affects the passive film properties. The source of nitrogen for DCT is the immersion media from which the nitrogen adsorbs onto the surface and later diffuses during high-temperature treatment into the outermost layers of the material as interstitially dissolved. The nitrogen incorporation is considered to occur through vacancies and intergranular spacings that are present in the martensitic lattice. Moreover, this incorporation could be the primary mechanism, which is latter accompanied in different environments by the secondary mechanism of formation of $\mathrm{NH}_{4}{ }^{+}$ions. This results in electro-potential discharge [37] of the newly formed "ghost layer" (passive layer) and reduced degradation of the material. 

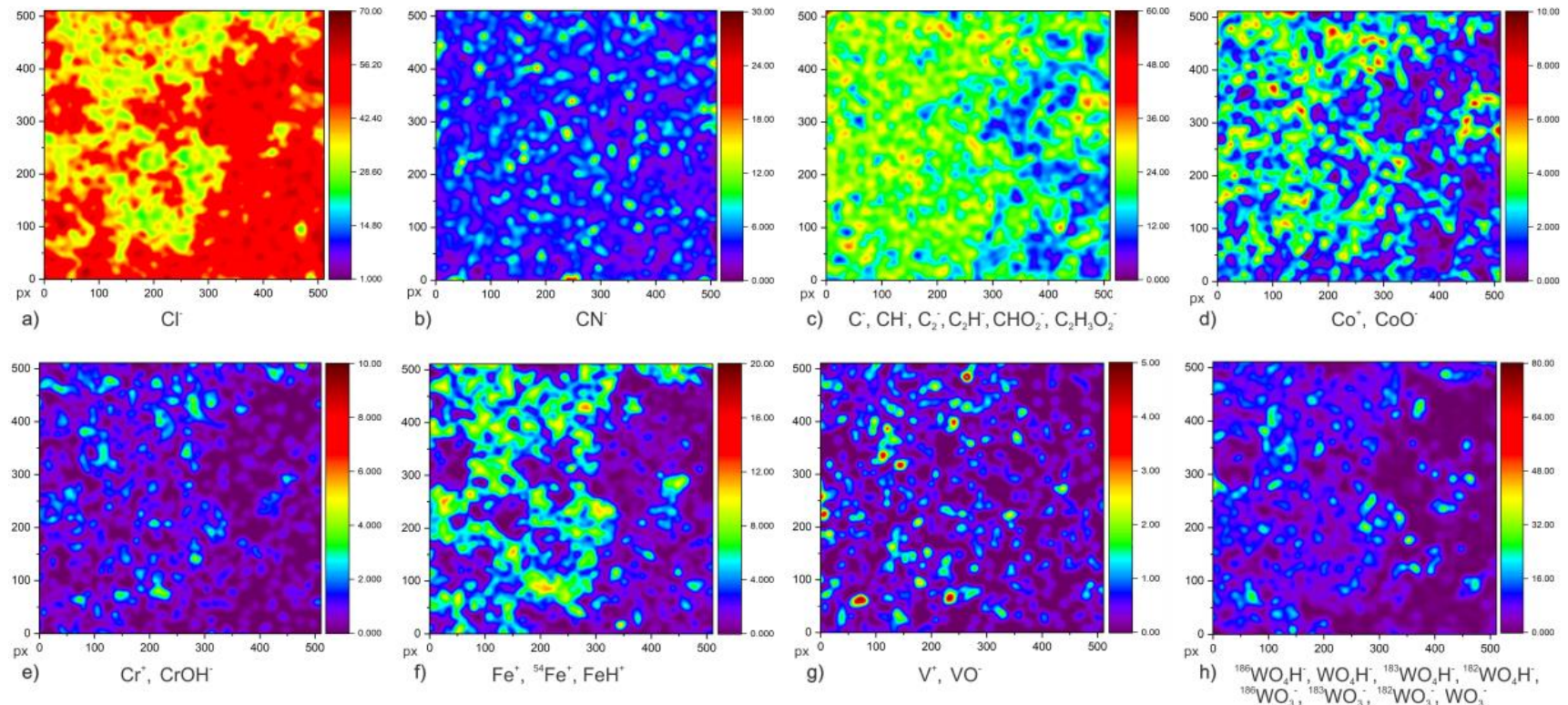

Figure 3. ToF-SIMS analysis of conventionally heat-treated sample (CHT) after 1 day of exposure in chloride-ions-enriched medium at $21^{\circ} \mathrm{C}$. (a) $\mathrm{Cl}^{-}$ions; (b) $\mathrm{CN}^{-}$ions; (c) $\mathrm{C}^{-}, \mathrm{CH}^{-}, \mathrm{C}_{2}^{-}$, $\mathrm{C}_{2} \mathrm{H}^{-}, \mathrm{CHO}_{2}{ }^{-}, \mathrm{C}_{2} \mathrm{H}_{2} \mathrm{O}_{2}{ }^{-}$ions; (d) $\mathrm{Co}^{+}, \mathrm{CoO}^{-}$ions; (e) $\mathrm{Cr}^{+}, \mathrm{CrOH}^{-}$ions; (f) $\mathrm{Fe}^{+},{ }^{54} \mathrm{Fe}^{+}, \mathrm{FeH}^{+}$ions; (g) $\mathrm{V}^{+}, \mathrm{VO}^{-}$ions; (h) ${ }^{186} \mathrm{WO}_{4} \mathrm{H}^{-}, \mathrm{WO}_{4} \mathrm{H}^{-},{ }^{183} \mathrm{WO}_{4} \mathrm{H}^{-},{ }^{182} \mathrm{WO}_{4} \mathrm{H}^{-},{ }^{186} \mathrm{WO}_{3}{ }^{-},{ }^{183} \mathrm{WO}_{3}{ }^{-},{ }^{182} \mathrm{WO}_{3}{ }^{-}$, $\mathrm{WO}_{3}{ }^{-}$ions.
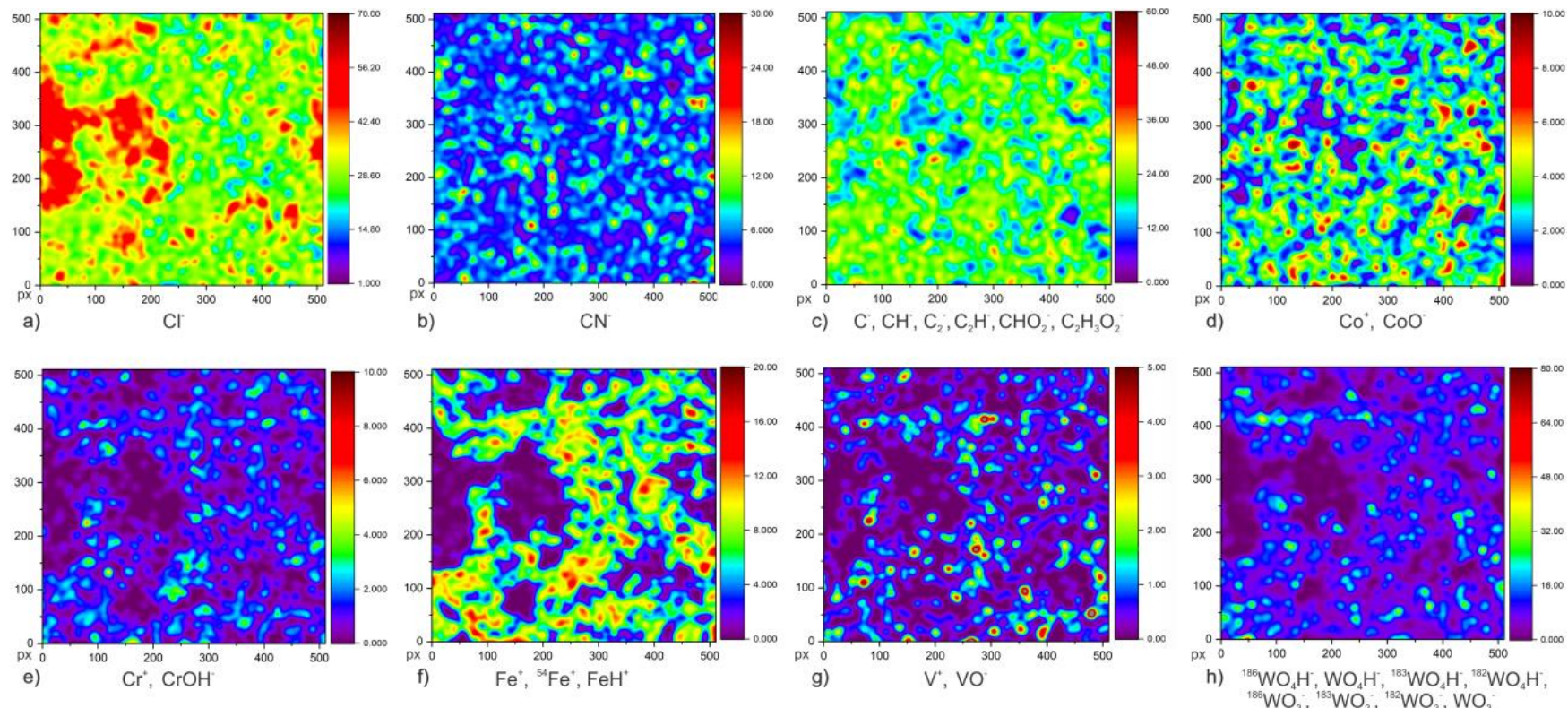

Figure 4. ToF-SIMS analysis of deep cryogenic heat-treated sample (DCT) after 1 day of exposure in chloride-ions-enriched medium at $21^{\circ} \mathrm{C}$. (a) $\mathrm{Cl}^{-}$ions; (b) $\mathrm{CN}^{-}$ions; (c) $\mathrm{C}^{-}, \mathrm{CH}^{-}, \mathrm{C}_{2}^{-}$, $\mathrm{C}_{2} \mathrm{H}^{-}, \mathrm{CHO}_{2}^{-}, \mathrm{C}_{2} \mathrm{H}_{2} \mathrm{O}_{2}^{-}$ions; (d) $\mathrm{Co}^{+}, \mathrm{CoO}^{-}$ions; (e) $\mathrm{Cr}^{+}, \mathrm{CrOH}^{-}$ions; (f) $\mathrm{Fe}^{+},{ }^{54} \mathrm{Fe}^{+}, \mathrm{FeH}^{+}$ions; (g) $\mathrm{V}^{+}, \mathrm{VO}^{-}$ions; (h) ${ }^{186} \mathrm{WO}_{4} \mathrm{H}^{-}, \mathrm{WO}_{4} \mathrm{H}^{-},{ }^{183} \mathrm{WO}_{4} \mathrm{H}^{-},{ }^{182} \mathrm{WO}_{4} \mathrm{H}^{-},{ }^{186} \mathrm{WO}_{3}{ }^{-},{ }^{183} \mathrm{WO}_{3}{ }^{-},{ }^{182} \mathrm{WO}_{3}{ }^{-}$, $\mathrm{WO}_{3}{ }^{-}$ions. 


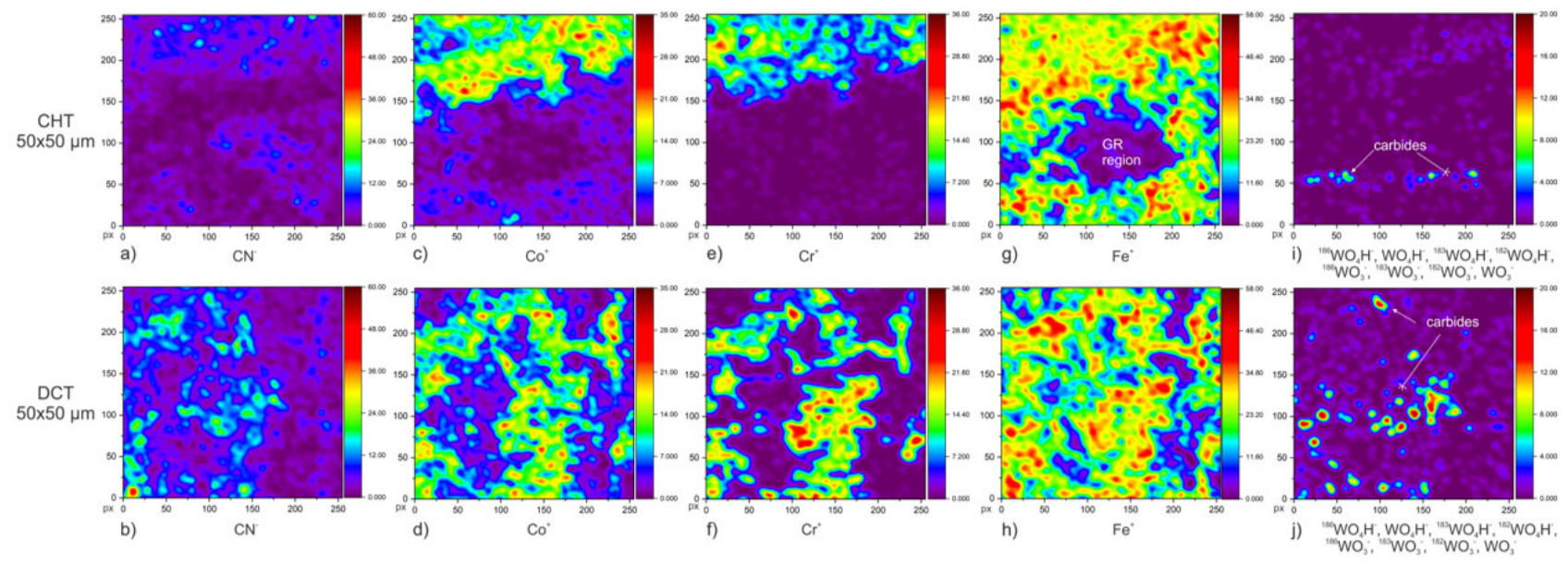

Figure 5. Higher magnification ToF-SIMS analysis of both conventionally (CHT) and deep cryogenic heat-treated samples (DCT) after 1 day of exposure in chloride-ions-enriched medium at $21^{\circ} \mathrm{C}$ for selected ion groups. (a,b) $\mathrm{CN}^{-}$ions; (c,d) $\mathrm{Co}^{+}$ions; $(\mathbf{e}, \mathbf{f}) \mathrm{Cr}^{+}$ions; $(\mathbf{g}, \mathbf{h}) \mathrm{Fe}^{+}$ions; $(\mathbf{i}, \mathbf{j}){ }^{186} \mathrm{WO}_{4} \mathrm{H}^{-}$, $\mathrm{WO}_{4} \mathrm{H}^{-},{ }^{183} \mathrm{WO}_{4} \mathrm{H}^{-},{ }^{182} \mathrm{WO}_{4} \mathrm{H}^{-},{ }^{186} \mathrm{WO}_{3}{ }^{-},{ }^{183} \mathrm{WO}_{3}{ }^{-},{ }^{182} \mathrm{WO}_{3}{ }^{-}, \mathrm{WO}_{3}{ }^{-}$ions.

The next alloying element analyzed was cobalt (ion forms of $\mathrm{Co}^{-}$and $\mathrm{CoO}^{-}$), Figures $3 \mathrm{~d}, 4 \mathrm{~d}$ and $5 \mathrm{~b}-\mathrm{g}$. Compared to other alloying elements of the investigated alloy, cobalt is mainly present in the martensitic matrix in the form of a solid solution. When comparing both samples, CHT (Figures 3d and 5c) and DCT (Figures 4d and 5d), no significant difference in distribution or abundance could be observed (the spatial distribution of corrosion crust was taken into account). Chromium distribution $\left(\mathrm{Cr}^{+}\right.$and $\mathrm{CrOH}^{-}$forms); Figures $3 \mathrm{e}, 4 \mathrm{e}$ and 5e,f, clearly indicates regions of carbides, which are the main source of chromium. However, from the maps and the corrosion crust analysis chromium was determined to not play a primary role in the corrosion resistance mechanism of the investigated alloy, neither for CHT nor DCT samples. This can be explained by the lower amount (4.10 wt.\%) of chromium compared to stainless steels (>10 wt.\%), for which $\mathrm{Cr}$ is the main contributor to the corrosion resistance. In the current case (AISI M35) cobalt in high content (4.52 wt.\%) has a prevalent role in corrosion resistance over chromium [38]. From this, and in general even distribution of $\mathrm{Co}$, it is postulated that the underlying passive film is partially formed from cobalt. Nevertheless, the higher local presence of chromium in Figure 5e,f indicates local pitting of the samples (evaluated in the next section), if not correlated to carbides. Similar relation of $\mathrm{Cr}$ with local pitting has been also observed in previous study with cross-sectional SEM investigation [13].

Iron distribution was measured by $\mathrm{Fe}^{+},{ }^{54} \mathrm{Fe}^{+}, \mathrm{FeH}^{+}$ions (Figures $3 \mathrm{f}, 4 \mathrm{f}$ and $5 \mathrm{~g}$, h). On one hand, the distribution of iron indicates the location of specific carbides when combined with other elemental maps $(\mathrm{C}, \mathrm{Cr}, \mathrm{W})$. On the other hand, the absence of iron species in the corrosion crust indicates the presence and position of GR I+II (Figure 5g,h and Figure 6), when associated with the characteristic elements ( $\mathrm{Cl}$ and S) of GR for CHT and DCT samples. The map distribution of vanadium $\left(\mathrm{V}^{+}, \mathrm{VO}^{-}\right.$ions) in $\mathrm{CHT}$ (Figure $3 \mathrm{~g}$ ) and DCT (Figure $4 \mathrm{~g}$ ) samples show the peaks corresponding to the distribution of carbides in the matrix. Due to its concentration in the investigated alloy (2.01 wt.\%), vanadium is not supposed to play an important role in the corrosion resistance of the samples. However, vanadium could theoretically help improve corrosion resistance by reducing both the formation of salt film and the formation rate of pits, as suggested by Ras et al. [39]. The distribution of the most abundant (6.22 wt.\%) alloying element, tungsten $\left({ }^{186} \mathrm{WO}_{4} \mathrm{H}^{-}, \mathrm{WO}_{4} \mathrm{H}^{-},{ }^{183} \mathrm{WO}_{4} \mathrm{H}^{-}\right.$, ${ }^{182} \mathrm{WO}_{4} \mathrm{H}^{-},{ }^{186} \mathrm{WO}_{3}{ }^{-},{ }^{183} \mathrm{WO}_{3}{ }^{-},{ }^{182} \mathrm{WO}_{3}{ }^{-}, \mathrm{WO}_{3}{ }^{-}$ions), shows localized concentrations, which correspond to carbides enriched by tungsten $\left(\mathrm{M}_{6} \mathrm{C}\right.$ [33]), present in both $\mathrm{CHT}$ (Figures $3 \mathrm{~h}$ and 5i) and DCT (Figures $4 \mathrm{~h}$ and $5 \mathrm{j}$ ) samples. No other significant information was obtained from tungsten distribution and its influence on corrosion resistance. 


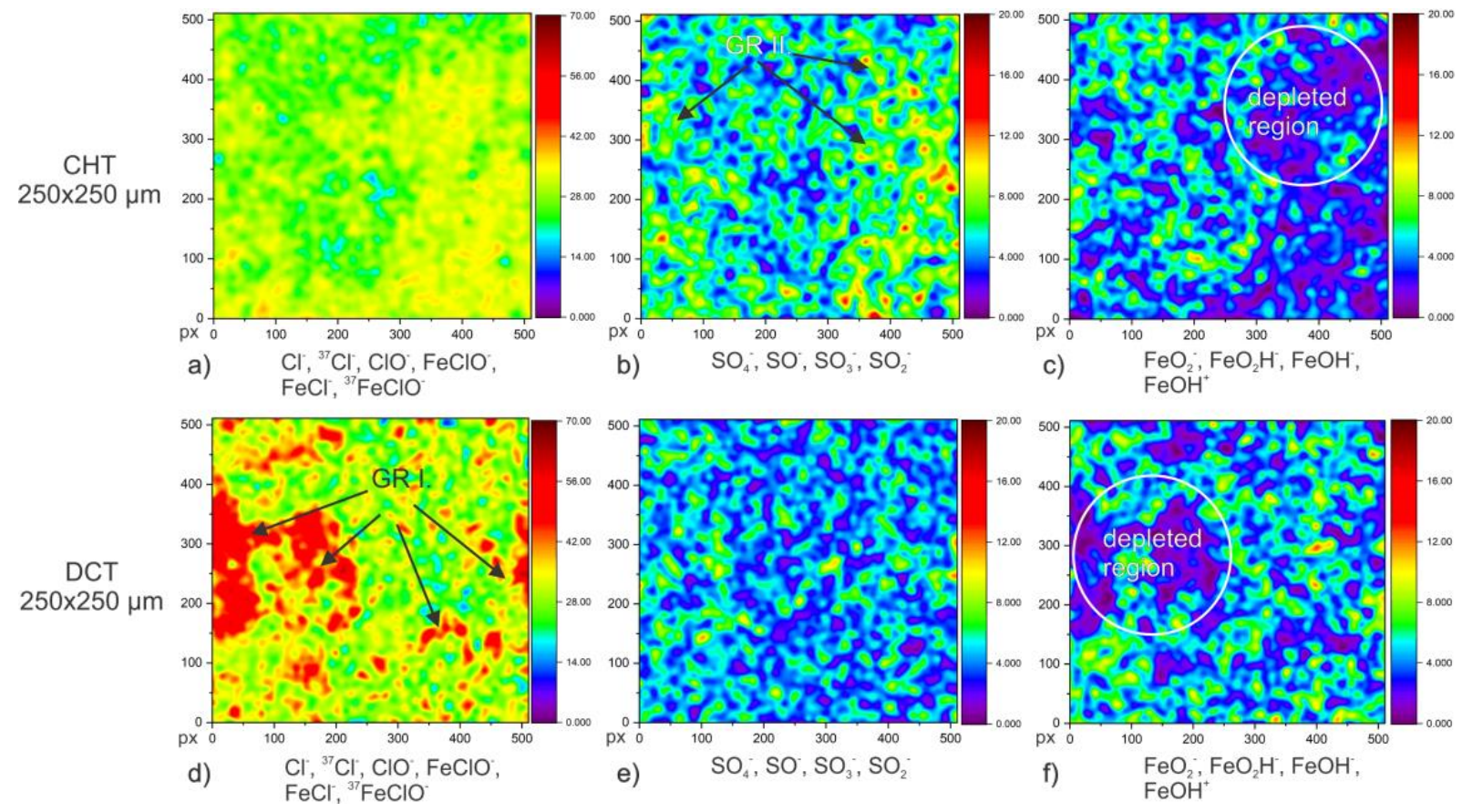

Figure 6. ToF-SIMS analysis of both conventionally (CHT) and deep cryogenic heat-treated samples (DCT) after 1 day of exposure in chloride-ions-enriched medium at $21^{\circ} \mathrm{C}$ for $(\mathbf{a}, \mathbf{d})$ green rust type I, $(\mathbf{b}, \mathbf{e})$ green rust type II and (c,f) Fe-oxides.

Figure 6 shows the distribution of green rust, type I (a,b) and type II (c,d), and Feoxides/hydroxides $(\mathrm{e}, \mathrm{f})$ on the samples surface. The ToF-SIMS analysis clearly shows the predominant formation of GR type $\mathrm{I}$ (combination of ions $\mathrm{Cl}^{-},{ }^{37} \mathrm{Cl}^{-}, \mathrm{ClO}^{-}, \mathrm{FeClO}^{-}$, $\mathrm{FeCl}^{-}$and ${ }^{37} \mathrm{FeClO}^{-}$) in the DCT sample, whereas GR type II (combination of ions $\mathrm{SO}_{4}{ }^{-}$, $\mathrm{SO}^{-}, \mathrm{SO}_{3}{ }^{-}$and $\mathrm{SO}_{2}{ }^{-}$) has higher abundance in the CHT sample, corresponding well with XRD results (Figure 1a). Absence or reduction of GR type II could not be linked to any improvement in corrosion resistance. Additionally, excessive presence of green rust was observed for the DCT sample compared to the CHT sample. The higher presence of GR for the DCT sample is associated with the increased concentration of nitrogen on the surface, which together with chlorine is the basis for the development of GR (excess amount of $\mathrm{NO}_{3}{ }^{-}, \mathrm{Cl}^{-}$and $\mathrm{NH}_{4}{ }^{+}$ions) [40]. This confirms our previous observations [13] and proposed theory that GR I plays an important role in the improvement of the corrosion resistance of the DCT sample. The proposed mechanism for improved corrosion resistance lies in the formation of GR I, as an inner part of the oxide layer formed over the passive layer. The GR I then acts as a buffer layer for the preferential development of magnetite, which is later covered by other Fe oxides/hydroxides as part of the oxide layer. Such a mechanism of GR preferential growth of magnetite was confirmed by Sumoondur et al. 2008 [41]. The distribution of GR was additionally correlated and confirmed with Fe-oxides/hydroxides, as indicated in Figure 6c,f.

\subsection{ToF-SIMS Depth Profiling}

ToF-SIMS depth profiling was performed with a negative ion charge. The ToF-SIMS depth profile analysis includes all corrosion products of the crust. The oxide layer is identified as the layer with an initial increase in oxides and hydroxides, which is defined as 0-2000 s of sputter time for the CHT sample and 0-1000 s for the DCT sample, respectively. The passive film is the region between the oxide layer and the metallic substrate, expressed as a second increase in the intensity of alloying elements (Figures 7 and 8). The passive film for CHT is 2000-3200 s and for DCT, 1000-3800 s of sputtering time, respectively. The region of metallic substrate is defined as the region of rapid decrease in oxides/hydroxides 
presence and constant value of alloying elements, which starts for the CHT sample after $3200 \mathrm{~s}$ and for the DCT sample after $3800 \mathrm{~s}$ of sputtering (Figures 7 and 8).
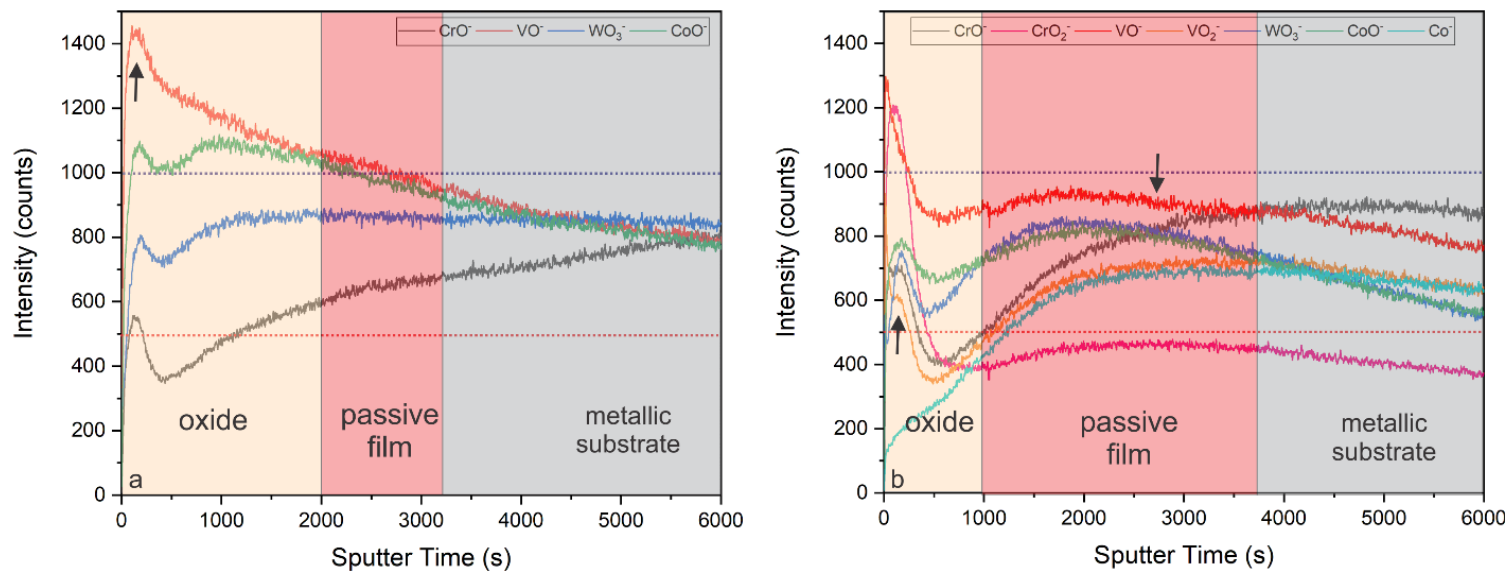

Figure 7. ToF-SIMS depth profiles (negative polarity) after 1 day exposure in chloride-ions-enriched medium at room conditions for selected alloying elements $\mathrm{Cr}, \mathrm{V}, \mathrm{W}$ and Co. (a) CHT sample and (b) DCT sample.
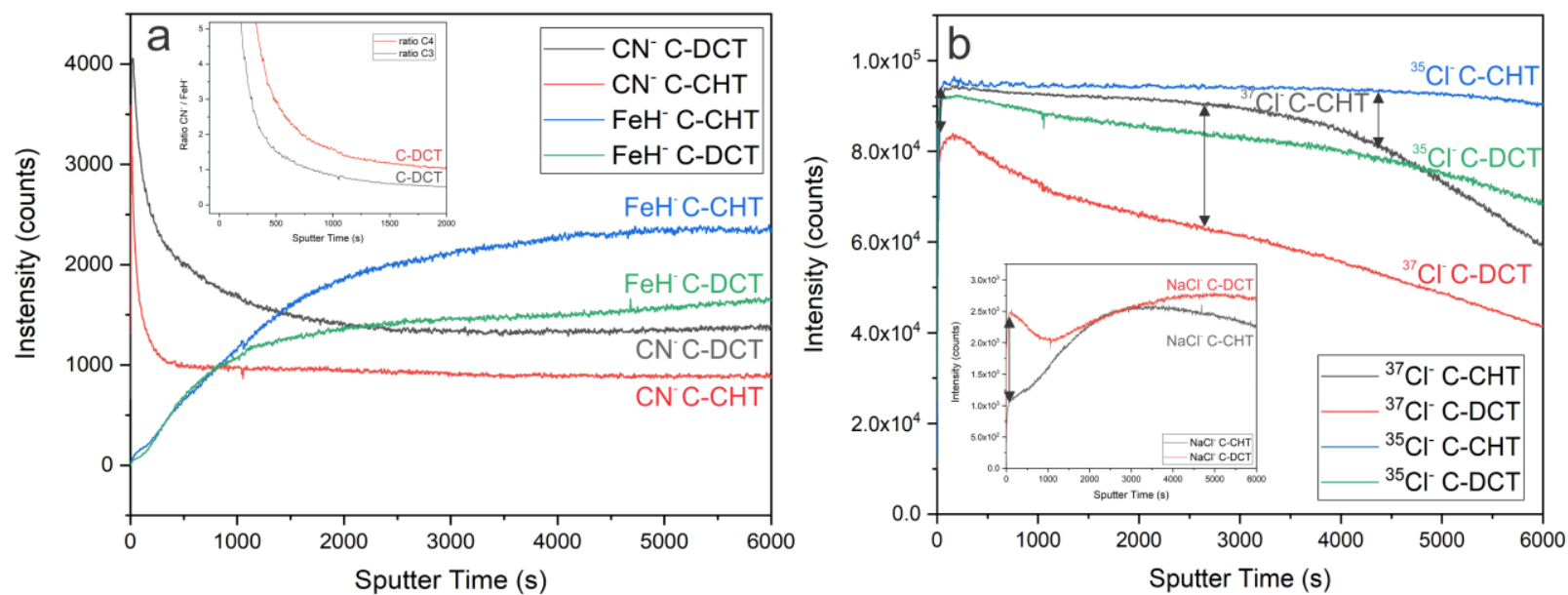

Figure 8. ToF-SIMS depth profiles (negative polarity) after 1 day exposure in chloride-ions-enriched medium at room conditions. (a) depth profile of nitrogen and iron and (b) depth profile of ${ }^{35} \mathrm{Cl}^{-}$, ${ }^{37} \mathrm{Cl}^{-}$and $\mathrm{NaCl}^{-}$.

When comparing the ions $\mathrm{CrO}^{-}, \mathrm{VO}^{-}, \mathrm{WO}_{3}{ }^{-}$and $\mathrm{CoO}^{-}$in $\mathrm{CHT}$ (Figure 7a) and DCT samples (Figure $7 \mathrm{~b}$ ), a more constant distribution of alloying elements throughout the passive film is observed for DCT compared to CHT. Additionally, the ions in CHT sample (Figure 7a) have higher intensity compared to DCT (Figure 7b), in both the oxide layer and passive film. $\mathrm{CrO}^{-}$, as a representative for chromium distribution, has its main peak at 130 s for the CHT sample (Figure 7a) and at $100 \mathrm{~s}$ of sputtering for the DCT sample (Figure $7 \mathrm{~b}$ ), followed by a continuous increase in intensity towards the metallic substrate. In addition to $\mathrm{CrO}^{-}, \mathrm{CrO}_{2}{ }^{-}$was also detected in the DCT sample, with its main peak at $\sim 125 \mathrm{~s}$ and then a significant drop occurring within the oxide layer. This significant drop indicates the inner layer of the oxide film, which is the transition layer between the outer oxide layer and the passive film. A similar structure of the oxide film has been reported by other researchers [42]. $\mathrm{VO}^{-}$results show main peaks at $~ 125 \mathrm{~s}$ of sputtering for CHT (Figure $7 \mathrm{a}$ ) and $\sim 25 \mathrm{~s}$ for the DCT (Figure $7 \mathrm{~b}$ ) sample. Afterwards, the intensity drops towards the value of the metallic substrate. However, for the DCT sample a peak of $\mathrm{VO}_{2}{ }^{-}$ ions is also observed at $\sim 20 \mathrm{~s}$. Tungsten ion $\mathrm{WO}_{3}{ }^{-}$signal shows a shift in the main peak 
of DCT to $\sim 1750 \mathrm{~s}$ (Figure $7 \mathrm{~b}$ ) compared to the CHT peak at $\sim 1180 \mathrm{~s}$ (Figure 7a). The results of $\mathrm{CoO}^{-}$, provided main peaks at $\sim 1050 \mathrm{~s}$ for CHT and at $2010 \mathrm{~s}$ for DCT. In the DCT sample species, Co- was also observed with a main peak at $\sim 3125 \mathrm{~s}$. These results and the initial peaks, which form due to the matrix effect [43] caused by oxide proximity, provide the correlation to the oxide thickness. The oxides for CHT are generally thicker and more enriched with the alloying elements $\mathrm{Cr}$ and $\mathrm{V}$ compared to DCT samples, which also correlates well with the ToF-SIMS spatial images and findings (Figures 3 and 4). The distribution and ratio of ions is also different, especially within the passive film, which clearly indicates different dynamics of the passive film development for both samples.

Considering the role of nitrogen in the DCT sample, the depth profile of $\mathrm{CN}^{-}$and $\mathrm{FeH}^{-}$was also analyzed. The $\mathrm{CN}^{-}$profile (Figure 8a) clearly shows a higher intensity of nitrogen in all surface layers (outer and inner layer of oxide film, and passive film) for the DCT sample compared to the CHT sample. In both cases the main peak is located at the beginning of the measurements. However, for the CHT sample a significantly stronger drop is present compared to DCT. The source of the nitrogen peak on the surface is related to the absorbed nitrogen and short-range diffusion from the quenching in nitrogen gas during heat treatment. However, for the DCT sample higher values of $\mathrm{N}$ below the material surface are a result of the DCT contribution, which is a consequence of the incorporation of nitrogen into the material during immersion into the liquid nitrogen. It is postulated that through boiling and bubbling and local high-pressure variations on the materials surface, the nitrogen is incorporated into the deeper portions of the material as well as adsorbed on the surface. Afterwards, during the heat treatment the surface-bounded nitrogen can diffuse deeper into the material due to the elevated temperatures of the tempering procedure $\left(>600^{\circ} \mathrm{C}\right)$. $\mathrm{FeH}^{-}$ was measured in order to determine the relative nitrogen presence within the iron matrix of both samples (Figure 8a). The ratio of $\mathrm{CN}^{-} / \mathrm{FeH}^{-}$confirms the increased presence of nitrogen in the DCT sample. This clearly indicates that DCT has an important role in the surface chemistry of the selected alloy, which can be also implicated on other similar alloys, in bulk or thin film form, when treated with DCT. Furthermore, in order to observe the surface chemistry dynamics of oxide and passive film formation in correlation to GR, the spectra of ${ }^{35} \mathrm{Cl}^{-},{ }^{37} \mathrm{Cl}^{-}$and $\mathrm{NaCl}^{-}$were investigated. The depth profile shows lower signal of both isotopes ${ }^{35} /{ }^{37} \mathrm{Cl}$ in the DCT sample, as in the CHT sample. The main peaks of ${ }^{35} \mathrm{Cl}^{-}$and ${ }^{37} \mathrm{Cl}^{-}$are at $\sim 315$ and at $\sim 245 \mathrm{~s}$ of sputtering for DCT and at $\sim 285$ and at $\sim 235 \mathrm{~s}$ for the CHT sample, respectively. Another interesting dynamic was observed for $\mathrm{NaCl}^{-}$. Beside the signal of $\mathrm{NaCl}^{-}$for DCT being higher compared to the CHT sample, it drops after the initial peak and then slowly increases to its main peak at $\sim 4810 \mathrm{~s}$. This indicates the change in surface chemistry. For CHT a lower initial signal is observed, followed by an increase, with the main peak at $2855 \mathrm{~s}$, and then a drop in the signal, indicating less stable passive film formation of the CHT sample. The ratio between isotopes for each sample could possibly indicate the preferable GR formation in each sample. However, to obtain clear and reliable results, an isotope tracking method by introduction of stable oxygen isotopes should be applied and tested in future studies.

The results show that the reason behind the higher corrosion resistance of the DCT sample can be attributed to the protective nature of the DCT-induced passive film, which is composed of nitrogen and oxides/hydroxides of alloying elements $(\mathrm{Cr}, \mathrm{Co}, \mathrm{V}, \mathrm{W})$, on which the GR type I grows and acts as a precursor for magnetite and, later, other corrosion products. The results also indicate that the oxide layer and passive film for the DCT sample are thicker compared to the CHT sample, which additionally indicates that a more physically stable corrosion layer forms, and with it increased corrosion resistance when applying DCT.

\subsection{Testing Effectiveness of Newly Characterized Passive Film Behavior for DCT-Treated High-Alloyed Ferrous Alloy}

In order to test the stability of the newly observed passive film induced by DCT, three different environments were chosen for testing the hypothesis of higher stability of 
passive film. CHT and DCT samples were exposed to different environments (C-control environment, T-increased temperature of chloride-ions-enriched medium $\left(100{ }^{\circ} \mathrm{C}\right)$ and $\mathrm{T}+\mathrm{V}$ increased temperature of chloride-ions-enriched medium $\left(100^{\circ} \mathrm{C}\right)$ and vibrations $(25 \mathrm{~Hz}$, $1 \mathrm{~h})$. In the first step, the composition of corrosion products in all three environments was measured. The XRD data, presented in Figure 9a, show the presence of different corrosion products. It is confirmed that for DCT, GR I forms after just $1 \mathrm{~h}$ of exposure, and this is observed for all three testing conditions, whereas GR II is mainly present in CHT samples and also forms after $1 \mathrm{~h}$ exposure in all conditions. The increased formation of magnetite can also be observed for DCT samples, compared to the CHT counterparts. Other corrosion products present in samples are calcium carbonate, halite, iron as matrix and goethite (Figure 9a). In the second step, the weight loss of each sample group (10 samples per group) was measured in order to observe the difference in corrosion performance between DCT and CHT samples. The average weight loss $(\mathrm{mg})$ after $1 \mathrm{~h}$ of exposure for all six testing groups is shown in Figure $9 \mathrm{~b}$. In the control group (room temperature, standard conditions) the weight loss and corrosion rate of CHT and DCT was $2.6 \pm 0.1 \mathrm{mg}$ and $0.03 \pm 0.001 \mathrm{~mm} / \mathrm{y}$, and $0.6 \pm 0.01 \mathrm{mg}$ and $0.006 \pm 0.0005 \mathrm{~mm} / \mathrm{y}$, respectively. Under the second condition (elevated temperature; $\mathrm{T}$ ), the weight loss increased due to the thermal influence on the corrosion propagation. Nevertheless, for the second condition the weight loss and corrosion rate were lower for DCT in comparison with CHT (CHT+T: $382.7 \pm 5 \mathrm{mg}$ and $4.11 \pm 0.1 \mathrm{~mm} / \mathrm{y} ; \mathrm{DCT}+\mathrm{T}: 302.4 \pm 3 \mathrm{mg}$ and $0.84 \pm 0.05 \mathrm{~mm} / \mathrm{y})$. Under the last condition with higher temperature and vibrations $(\mathrm{T}+\mathrm{V})$, the weight loss and corrosion rate for CHT and DCT samples are $77.7 \pm 2 \mathrm{mg}$ and $3.25 \pm 0.1 \mathrm{~mm} / \mathrm{y}$, and $36 \pm 2 \mathrm{mg}$ and $0.39 \pm 0.01 \mathrm{~mm} / \mathrm{y}$, respectively. In all three environments, the DCT samples display improved corrosion properties, which is clearly emphasized in conditions with a higher temperature. The data suggest that the DCT-induced passive film actively increases material corrosion resistance. The improvement in control environment is $75 \%$ in terms of weight loss and $80 \%$ in corrosion rate. In a high-temperature environment improvement is $20 \%$ and $79 \%$, and in a high-temperature environment combined with vibrations it is $53 \%$ and $88 \%$, respectively.
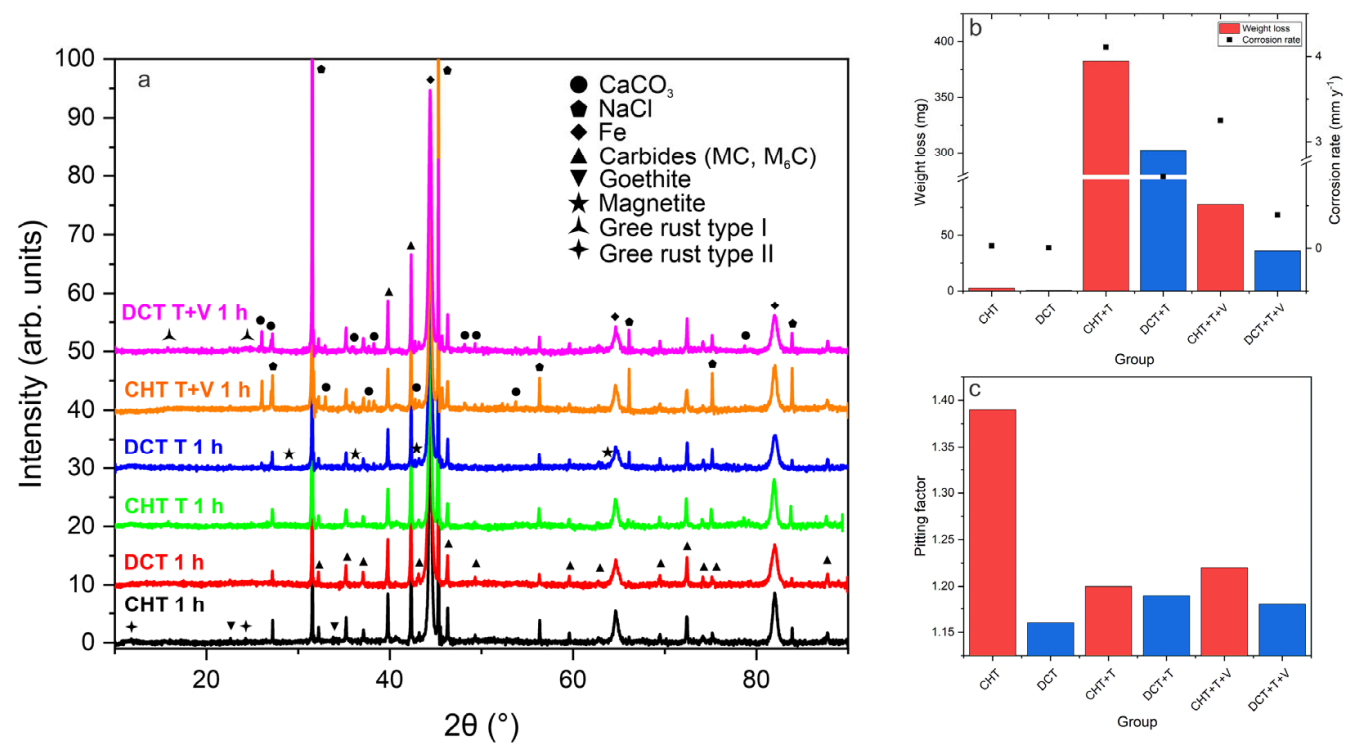

Figure 9. (a) XRD data for control samples (CHT, DCT) and samples (CHT+T, DCT+T, CHT+T+V, $\mathrm{DCT}+\mathrm{T}+\mathrm{V}$ ) tested in two different environments; T-higher temperature and $\mathrm{T}+\mathrm{V}$-higher temperature and vibrations. (b) Weight loss (columns) and corrosion rate (black dots); (c) pitting factor of each sample group.

In order to test the stability of the newly observed passive film induced by DCT, three different environments were chosen to test the hypothesis of the higher stability of 
passive film. CHT and DCT samples were exposed to different environments (C-control environment, T-increased temperature of chloride-ions-enriched medium $\left(100{ }^{\circ} \mathrm{C}\right)$ and $\mathrm{T}+\mathrm{V}$ increased temperature of chloride-ions-enriched medium $\left(100^{\circ} \mathrm{C}\right)$ and vibrations $(25 \mathrm{~Hz}$, $1 \mathrm{~h})$. In the first step, the composition of corrosion products in all three environments was measured. The XRD data, presented in Figure 9a, shows presence of different corrosion products. It is confirmed that for DCT GR I forms after just $1 \mathrm{~h}$ of exposure, observed for all three testing conditions. Whereas GR II is mainly present in CHT samples and also forms already after $1 \mathrm{~h}$ exposure in all conditions. The increased formation of magnetite can also be observed for DCT samples, compared to its CHT counterparts. Other corrosion products present in samples are calcium carbonate, halite, iron as matrix and goethite (Figure 9a). In the second step the weight loss of each sample group (10 samples per group) was measured in order to observe the difference in corrosion performance between DCT and CHT samples. The average weight loss ( $\mathrm{mg}$ ) after $1 \mathrm{~h}$ of exposure for all six testing groups is shown in Figure $9 \mathrm{~b}$. In the control group (room temperature, standard conditions) the weight loss and corrosion rate of CHT and DCT was $2.6 \pm 0.1 \mathrm{mg}$ and $0.03 \pm 0.001 \mathrm{~mm} / \mathrm{y}$, and $0.6 \pm 0.01 \mathrm{mg}$ and $0.006 \pm 0.0005 \mathrm{~mm} / \mathrm{y}$, respectively. Under the second condition (elevated temperature; T), the weight loss increased due to the thermal influence on the corrosion propagation. Nevertheless, for the second condition the weight loss and corrosion rate were lower for DCT in comparison to CHT (CHT+T: $382.7 \pm 5 \mathrm{mg}$ and $4.11 \pm 0.1 \mathrm{~mm} / \mathrm{y}$; $\mathrm{DCT}+\mathrm{T}: 302.4 \pm 3 \mathrm{mg}$ and $0.84 \pm 0.05 \mathrm{~mm} / \mathrm{y})$. Under the last condition with higher temperature and vibrations $(\mathrm{T}+\mathrm{V})$, the weight loss and corrosion rate for $\mathrm{CHT}$ and DCT samples are $77.7 \pm 2 \mathrm{mg}$ and $3.25 \pm 0.1 \mathrm{~mm} / \mathrm{y}$, and $36 \pm 2 \mathrm{mg}$ and $0.39 \pm 0.01 \mathrm{~mm} / \mathrm{y}$, respectively. In all three environments, the DCT samples display improved corrosion properties, which is clearly emphasized in conditions with higher temperature. The data suggest that the DCT-induced passive film actively increases material corrosion resistance. The improvement in the control environment is $75 \%$ in terms of weight loss and $80 \%$ in terms of the corrosion rate. In a high-temperature environment the improvement is 20 and $79 \%$, and in a high-temperature environment combined with vibrations it is 53 and $88 \%$, respectively.

\section{Conclusions}

In this work the role of nitrogen, introduced by deep cryogenic treatment, was investigated in relation to the surface modification of high-alloyed ferrous alloy. Using time-of-flight secondary ion mass spectroscopy (ToF-SIMS), the nitrogen was confirmed to be present in a larger quantity in DCT samples compared to their conventionally heattreated (CHT) counterparts. The nitrogen acts as a building block for the formation of a thin corrosion buffer layer dubbed as a ghost layer, which facilitates the preferential formation of green rust type I. The modification is considered to result from the formation of additional ion species $\left(\mathrm{NO}_{3}{ }^{-}\right.$and $\left.\mathrm{NH}_{4}{ }^{+}\right)$that modify the local environment and ionic exchange between the alloy surface and corrosive medium. In turn, the green rust layer acts as a precursor for the formation of magnetite, which reduces the corrosion propagation due to its high density. As a result, the DCT samples exhibit lower corrosion rates and wear loss, which was also confirmed in more extreme environments that involved elevated temperatures and vibrations. From these experiments it was confirmed that the DCT-/1nduced passive film is more stable than the passive film of the CHT counterpart. Furthermore, the modified passivation of the material with DCT leads to different corrosion product development to when the material is conventionally heat-treated. DCT also induces changes in the inclusion of the different alloying elements in the formation of the passivation layer as well as the formation of different ionic species that were detected and monitored with ToF-SIMS. The presence of different ions indicates a change in the oxidation behavior of the metallic surface as well as the formation of different oxides, which goes hand in hand with our previous findings on the alloy's oxidation dynamics in air. With these results, this study provides the first proof of the influence of DCT on surface behavior through 
incorporation of nitrogen into a sample surface, and with it an answer to the improved corrosion response of the ferrous alloys in a chloride-ions-enriched environment.

Supplementary Materials: The following supporting information can be downloaded at: https: //www.mdpi.com/article/10.3390/coatings12020213/s1.

Author Contributions: Conceptualization, P.J.-K., M.J.-K. and B.P.; methodology, P.J.-K. and M.J.K.; investigation, P.J.-K. and M.J.-K.; resources, P.J.-K.; writing_original draft preparation, P.J.-K. and M.J.-K.; writing—review and editing, P.J.-K., M.J.-K. and B.P.; visualization, P.J.-K. and M.J.-K.; supervision, B.P. All authors have read and agreed to the published version of the manuscript.

Funding: This research was funded by Slovenian Research Agency (ARRS), Ljubljana, Slovenia, Grant Nos. P2-0050 and J2-9211.

Institutional Review Board Statement: Not applicable.

Informed Consent Statement: Not applicable.

Data Availability Statement: The raw processed data required to reproduce these findings cannot be shared at this time as the data also form part of an ongoing study.

Acknowledgments: Acknowledgement goes to T. Kranjec (IMT, Slovenia) for the help in the metallographic lab. For seawater data, authors thank K. Klun, Marine Biology Station, National Institute of Biology, Slovenia. For the help with ToF-SIMS spectra authors would like to thank N. Valle from LIST, Luxembourg; and J. Kovač and J. Ekar from Jožef Stefan Institute, Slovenia.

Conflicts of Interest: The authors declare no competing interests.

\section{References}

1. Voglar, J; Novak, Ž.; Jovičević-Klug, P.; Podgornik, B.; Kosec, T. Effect of deep cryogenic treatment on corrosion properties of various high-speed steels. Metals 2020, 11, 14. [CrossRef]

2. Popoola, L.T.; Grema, A.S.; Latinwo, G.K.; Gutti, B.; Balogun, A.S. Corrosion problems during oil and gas production and its mitigation. Int. J. Ind. Chem. 2013, 4, 1-15. [CrossRef]

3. Eliaz, N. Corrosion of metallic biomaterials: A review. Materials 2019, 12, 407. [CrossRef]

4. Comizzoli, R.B.; Frankenthal, R.P.; Milner, P.C.; Sinclair, J.D. Corrosion of electronic materials and devices. JSTOR 1986, 234, 340-345. [CrossRef]

5. LeBozec, N.; Blandin, N.; Thierry, D. Accelerated corrosion tests in the automotive industry: A comparison of the performance towards cosmetic corrosion. Mater. Corros. 2008, 59, 889-894. [CrossRef]

6. Benavides, S. Corrosion in the aerospace industry. Corros. Control Aerosp. Ind. 2009, 1-14. [CrossRef]

7. Cattant, F.; Crusset, D.; Féron, D. Corrosion issues in nuclear industry today. Mater. Today 2008, 11, 32-37. [CrossRef]

8. Park, J.Y.; Park, Y.S. The effects of heat-treatment parameters on corrosion resistance and phase transformations of $14 \mathrm{Cr}-3 \mathrm{Mo}$ martensitic stainless steel. Mater. Sci. Eng. A 2007, 448-451, 1131-1134. [CrossRef]

9. Fundazioa, E. Cryogenic Treatment Improves the Characteristics of Materials and Cuts Their Costs-ScienceDaily. Available online: https:/ / www.sciencedaily.com/releases/2014/03/140319085424.htm (accessed on 19 July 2021).

10. Jovičević-Klug, P.; Podgornik, B. Review on the effect of deep cryogenic treatment of metallic materials in automotive applications. Metals 2020, 10, 434. [CrossRef]

11. Tóth, L. Examination of the properties and structure of tool steel EN 1.2379 due to different heat treatments. Eur. J. Mater. Sci. Eng. 2018, 3, 1-7.

12. Gogte, C.L.; Peshwe, D.R.; Paretkar, R.K. Influence of Cobalt on the Cryogenically Treated W-Mo-V High Speed Steel. In Proceedings of the Advances in Cryogenic Engineering, Spokane, WA, USA, 12-14 June 2012; pp. 1175-1182.

13. Jovičević-Klug, M.; Jovičević-Klug, P.; Kranjec, T.; Podgornik, B. Cross-effect of surface finishing and deep cryogenic treatment on corrosion resistance of AISI M35 steel. J. Mater. Res. Technol. 2021, 14, 2365-2381. [CrossRef]

14. Hemath Kumar, G.; Mohit, H.; Purohit, R. Effect of deep cryogenic treatment on composite material for automotive Ac system. Mater. Today Proc. 2017, 4, 3501-3505. [CrossRef]

15. Jovičević-Klug, P.; Jenko, M.; Jovičević-Klug, M.; Šetina Batič, B.; Kovač, J.; Podgornik, B. Effect of deep cryogenic treatment on surface chemistry and microstructure of selected high-speed steels. Appl. Surf. Sci. 2021, 548, 1-11. [CrossRef]

16. Kim, B.; Kim, S.; Kim, H. Effects of alloying elements ( $\mathrm{Cr}, \mathrm{Mn}$ ) on corrosion properties of the high-strength steel in $3.5 \% \mathrm{NaCl}$ solution. Adv. Mater. Sci. Eng. 2018, 2018, 1-13. [CrossRef]

17. Hou, X.; Gao, L.; Cui, Z.; Yin, J. Corrosion and protection of metal in the seawater desalination. IOP Conf. Ser. Earth Environ. Sci. 2018, 108, 022037. [CrossRef]

18. $\mathrm{Fu}, \mathrm{Y}$.; $\mathrm{Wu}, \mathrm{X} . ; \mathrm{Han}, \mathrm{E} . \mathrm{H} . ; \mathrm{Ke}, \mathrm{W} . ;$ Yang, K.; Jiang, Z. Effects of nitrogen on the passivation of nickel-free high nitrogen and manganese stainless steels in acidic chloride solutions. Electrochim. Acta 2009, 54, 4005-4014. [CrossRef] 
19. Grabke, H.J. The role of nitrogen in the corrosion of iron and steels. ISIJ Int. 1996, 36, 777-786. [CrossRef]

20. Leskovšek, V.; Podgornik, B. Simultaneous ion nitriding and tempering after deep cryogenic treatment of PM S390MC HSS. Int. Heat Treat. Surf. Eng. 2013, 7, 115-119. [CrossRef]

21. Olefjord, I.; Clayton, C.R. Surface composition of stainless steel during active dissolution and passivation. ISIJ Int. 1991, 31, 134-141. [CrossRef]

22. Olefjord, I.; Wegrelius, L. The influence of nitrogen on the passivation of stainless steels. Corros. Sci. 1996, 38, 1203-1220. [CrossRef]

23. Ramesh, S.; Bhuvaneshwari, B.; Palani, G.S.; Mohan Lal, D.; Mondal, K.; Gupta, R.K. Enhancing the corrosion resistance performance of structural steel via a novel deep cryogenic treatment process. Vacuum 2019, 159, 468-475. [CrossRef]

24. Ramesh, S.; Bhuvaneswari, B.; Palani, G.S.; Lal, D.M.; Iyer, N.R. Effects on corrosion resistance of rebar subjected to deep cryogenic treatment. J. Mech. Sci. Technol. 2017, 31, 123-132. [CrossRef]

25. Bensely, A.; Shyamala, L.; Harish, S.; Mohan Lal, D.; Nagarajan, G.; Junik, K.; Rajadurai, A. Fatigue behaviour and fracture mechanism of cryogenically treated En 353 steel. Mater. Des. 2009, 30, 2955-2962. [CrossRef]

26. Cai, Y.; Luo, Z.; Zeng, Y. Influence of deep cryogenic treatment on the microstructure and properties of AISI304 austenitic stainless steel A-TIG weld. Sci. Technol. Weld. Join. 2017, 22, 236-243. [CrossRef]

27. Baldissera, P.; Delprete, C. Deep cryogenic treatment of AISI 302 stainless steel: Part II-fatigue and corrosion. Mater. Des. 2010, 31 , 4731-4737. [CrossRef]

28. Tian, J.; Wang, W.; Shahzad, M.B.; Yan, W.; Shan, Y.; Jiang, Z.; Yang, K. A new maraging stainless steel with excellent strengthtoughness-corrosion synergy. Materials 2017, 10, 1293. [CrossRef]

29. Tian, J.L.; Wang, W.; Shahzad, M.B.; Yan, W.; Shan, Y.Y.; Jiang, Z.H.; Yang, K. Corrosion resistance of Co-containing maraging stainless steel. Acta Metall. Sin. (Engl. Lett.) 2018, 31, 785-797. [CrossRef]

30. Hsu, H.W.; Tsai, W.T. High temperature corrosion behavior of siliconized 310 stainless steel. Mater. Chem. Phys. 2000, 64, 147-155. [CrossRef]

31. Vasyliev, G.S.; Novosad, A.A.; Pidburtnyi, M.O.; Chyhryn, O.M. Influence of ultrasound vibrations on the corrosion resistance of heat-exchange plates made of AISI 316 steel. Mater. Sci. 2019, 54, 913-919. [CrossRef]

32. ASTM Standard Practice for Preparing, Cleaning, and Evaluating Corrosion Test Specimens; ASTM International: West Conshohocken, PA, USA, 1999; pp. 1-8.

33. Jovičević-Klug, P.; Jovičević-Klug, M.; Podgornik, B. Effectiveness of deep cryogenic treatment on carbide precipitation. J. Mater Res. Technol. 2020, 9, 13014-13026. [CrossRef]

34. Stephan, T. TOF-SIMS in Cosmochemistry. Planet. Space Sci. 2001, 49, 859-906. [CrossRef]

35. Jovičević-Klug, P.; Kranjec, T.; Jovičević-Klug, M.; Podgornik, B. Modification of Steel Corrosion Resistance in Seawater with Deep Cryogenic Treatment. In Proceedings of the Proceedings of the 60th Conference of Metallurgists, COM 2021: The Canadian Institute of Mining, Metallurgy and Petroleum, Toronto, ON, Canada, 16-19 August 2021; pp. 1-4.

36. Esmaily, M.; Malmberg, P.; Shahabi-Navid, M.; Svensson, J.E.; Johansson, L.G. A ToF-SIMS Investigation of the Corrosion Behavior of Mg Alloy AM50 in Atmospheric Environments. Appl. Surf. Sci. 2016, 360, 98-106. [CrossRef]

37. Ghanem, W.A. Effect of Nitrogen on the Corrosion Behavior of Austenitic Stainless Steel in Chloride Solutions. In Proceedings of the EUROCORR 2004-European Corrosion Conference: Long Term Prediction and Modelling of Corrosion, Toronto, ON, Canada, 12-14 July 2004; pp. 1-8. [CrossRef]

38. Metikoš-Huković, M.; Babić, R. Passivation and corrosion behaviours of cobalt and cobalt-chromium-molybdenum alloy. Corros. Sci. 2007, 49, 3570-3579. [CrossRef]

39. Ras, M.H.; Pistorius, P.C. Possible mechanisms for the improvement by vanadium of the pitting corrosion resistance of $18 \%$ chromium ferritic stainless steel. Corros. Sci. 2002, 44, 2479-2490. [CrossRef]

40. Alcántara, J.; de la Fuente, D.; Chico, B.; Simancas, J.; Díaz, I.; Morcillo, M. Marine atmospheric corrosion of carbon steel: A review. Materials 2017, 10, 406. [CrossRef]

41. Sumoondur, A.; Shaw, S.; Ahmed, I.; Benning, L.G. Green rust as a precursor for magnetite: An in situ synchrotron based study. Mineral. Mag. 2008, 72, 201-204. [CrossRef]

42. Wang, Z.; Paschalidou, E.M.; Seyeux, A.; Zanna, S.; Maurice, V.; Marcus, P. Mechanisms of Cr and Mo enrichments in the passive oxide film on 316L austenitic stainless steel. Front. Mater. 2019, 6, 1-12. [CrossRef]

43. Priebe, A.; Xie, T.; Bürki, G.; Pethö, L.; Michler, J. The matrix effect in TOF-SIMS analysis of two-element inorganic thin films. J. Anal. At. Spectrom. 2020, 35, 1156-1166. [CrossRef] 